\title{
Identification by cell electrophoresis of a subpopulation of polymorphonuclear cells which is increased in patients with rheumatoid arthritis and certain other rheumatological disorders
}

\author{
K A BROWN,' J D PERRY, ${ }^{2}$ C BLACK, ${ }^{3}$ AND D C DUMONDE'
}

From the 'Department of Immunology, United Medical and Dental Schools, St Thomas's Campus, London; the ${ }^{2}$ Department of Rheumatology, The London Hospital; and the ${ }^{3}$ Department of Rheumatology, West Middlesex University Hospital

SUMmARY Two and occasionally three electrophoretic subpopulations of polymorphonuclear cells (PMNs) were indentified in the blood of normal healthy subjects and patients with rheumatoid arthritis (RA). Most of the PMNs from both groups of subjects were found in the population with the highest surface charge; the remainder being in the other distributions, which were collectively termed the slow cell population. There was a significant increase in the percentage of rheumatoid PMNs (mean $42 \%$ ) ascribed to the slow population when compared with PMNs from normal subjects (mean 17\%). A similar increase in the slow cell population was also seen in patients with Felty's syndrome (mean $38 \%$ ) and scleroderma (mean $51 \%$ ), but not in patients with Behçet's syndrome (mean 18\%). Synovial fluid aspirated from the knee joints of patients with RA contained PMNs with the lowest surface charge. With nylon fibre as an adherence substrate cells of a low surface charge were found to be more adherent than those of a high surface charge. An alteration in the electrophoretic distribution of PMNs may represent changes that are related to the expression of functionally related membrane ionogenic groups.

The polymorphonuclear cell (PMN) is the major infiltrating leucocyte in the synovial fluid in inflammatory joints of patients with rheumatoid arthritis (RA). Within this environment the extracellular release of lysosomal enzymes ${ }^{1}$ and oxygen radicals ${ }^{2}$ from PMNs may contribute to changes that underlie the pathogenesis of joint damage.

Because the half life of the synovial fluid PMN in RA is approximately four hours and the daily turnover of PMNs in a rheumatoid knee joint has been estimated at over one million cells, ${ }^{3}$ there must be a continued extravasation of PMNs from the circulation into the joint in order to maintain the high local concentration of these cells. The question arises of whether such PMNs represent a selected subpopulation of cells whose functional characteristics favour diapedesis into the rheumatoid joint.

Cell electrophoresis permits the indirect measure-

Accepted for publication 28 October 1987.

Correspendence to Dr K A Brown. Department of Immunology. The Rayne Institute. St Thomas's Ilospital, Lendon SE1 7 E.H. ment of surface ionogenic groups, whose expression may reflect the status of a cell's functional activity. The maturation stages of the human PMNs in the bone marrow are associated with a decrease in electrophoretic mobility (EPM), ${ }^{4}$ whereas treatment of macrophages with agents that reduce the surface charge results in an enhancement of phagocytosis. ${ }^{5} \mathrm{~h}$

Earlier studies had shown that the surface charge of PMNs from a small number of patients with RA was lower than that of PMNs from normal subjects ${ }^{7}$ and that cells of a high surface charge were less adherent than those with a low surface charge. ${ }^{8}$ It was the aim of the present study to confirm and extend those findings by analysing PMNs from a larger number of patients not only with RA but also with other selected rheumatological disorders. Furthermore, investigations were undertaken to assess the adherent properties of the electrophoretic subpopulations of rheumatoid PMNs, and to compare the surface charge of synovial fluid PMNs with that of blood PMNs from patients with RA. 


\section{Patients and methods}

PATIENTS AND CONTROLS

Blood was collected from 53 patients with definite or classical RA" and seven patients with Felty's syndrome, all of whom had neutropenia (mean $\left.1.41 \times 10^{9} / 1\right)$. In addition, blood samples were obtained from 12 patients who satisfied the American Rheumatism Association criteria for scleroderma $^{10}$ and 11 patients with Behçet's syndrome who fulfilled the criteria of Mason and Barnes. ${ }^{11}$ The control panel consisted of 69 blood samples taken from 46 healthy hospital personnel. Eleven of the normal subjects donated blood on two to five occasions during the study.

\section{SEPARATION OF PMNS}

The method was a modification of that of Dioguardi et al. ${ }^{12}$ Twenty millilitres of heparinised blood (10 $\mathrm{U} / \mathrm{ml}$ ) was diluted with $140 \mathrm{ml}$ of $(0.83 \%$ ammonium chloride and allowed to stand for 10 minutes at room temperature. After centrifuging at $450 \mathrm{~g}$ for 10 minutes the supernatant was discarded and the $\mathrm{NH}_{4} \mathrm{Cl}$ lysis stage repeated. The PMN pellet from the second lysis was washed three times by slow centrifugation ( $55 \mathrm{~g}$ for 10 minutes) in calcium and magnesium free Hank's balanced salt solution. This slow centrifugation separated the large dense PMNs from the smaller less dense lymphocytes, which remained in suspension. The absence of divalent cations in the medium prevented any spontaneous aggregation of the PMNs and greatly increased the yield of cells. The final cell pellet was adjusted to $1 \times 10^{6}$ cells $/ \mathrm{ml}$. Cell viability as shown by exclusion of the trypan blue was always $>96 \%$, and the purity of PMNs was approximately $90 \%$. Once separated, the PMNs were subjected to electrophoretic analysis.

For the isolation of PMNs from the synovial fluid of patients with RA the fluid aspirated from knee joints in the course of treatment was incubated with $75 \mathrm{U} / \mathrm{ml}$ lyalase for 30 minutes at $37^{\circ} \mathrm{C}$ before dilution with ammonium chloride.

\section{CELL ELECTROPHORESIS}

A detailed description of the apparatus used for electrophoretic analysis and its application in the measurement of surface charge has been given elsewhere. ${ }^{13}$ PMNs were suspended at $1 \times 10^{6}$ cells/ $\mathrm{ml}$ in Medium 199 containing $20 \mathrm{nmol} / \mathrm{l}$ HEPES $\left(N-2\right.$ - hydroxyethylpiperazine - $N^{\prime}-2$ - ethanesul-

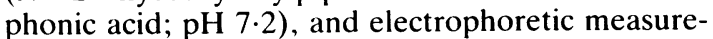
ments were made on $1 \mathrm{ml}$ samples in a cylindrical electrophoretic assembly (manufactured by Rank Bros, Bottisham, Cambridge). Both electrode and capillary chambers were kept at a constant $24^{\circ} \mathrm{C}$ and contained Medium 199, $\mathrm{pH} 7 \cdot 2$. A polarising $\square$ voltage of $60 \mathrm{~V}$ produced a $4 \mathrm{~mA}$ current through the capillary, resulting in a field strength of $8.0=$ V.cm ${ }^{-1}$.

For each determination $100 \mathrm{PMNs}$ were scored and the EPM, expressed as $\mu \mathrm{m} . \mathrm{cm} . \mathrm{s}^{-1} \cdot \mathrm{V}^{-1}$, calculated from the following equation:

$$
\underset{\left(\mu \mathrm{m} \cdot \mathrm{cm} \cdot \mathrm{s}^{-1} \cdot \mathrm{V}^{-1}\right)}{\mathrm{EPM}}=\frac{\text { distance migrated }(25 \mu \mathrm{m})}{\text { time }(\mathrm{s}) / \text { field strength }\left(\mathrm{V} \cdot \mathrm{cm}^{-1}\right)}
$$

If the distance migrated by the cells and the field strength applied are known the only variable needed to calculate the EPM is the migration time of the cells, to an accuracy of $1 / 40 \mathrm{~S}$, over this fixed distance. By reversing the polarity each cell was timed over the same distance but in the opposite direction and mean values accepted from pairs of timings with less than $5 \%$ variation. Results were subjected to probit analysis to test for departures from normal distribution. ${ }^{14}$ Subpopulations of cells with distinct differences in surface charge were distinguished from plots of probits against EPM values. Deviations from linearity implied the presence of more than one population of cells.

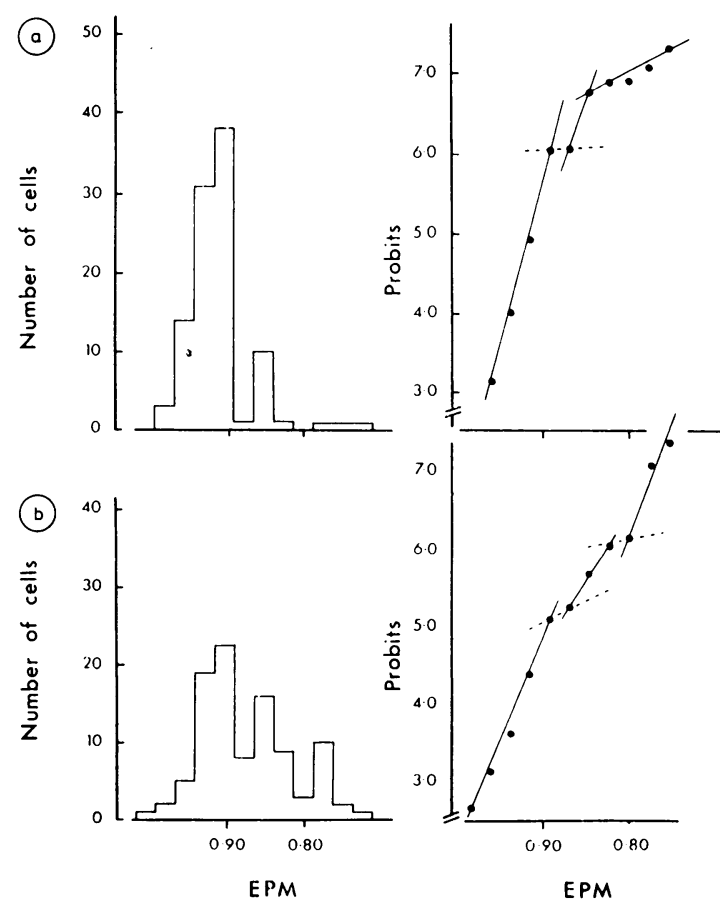

Fig. 1 Electrophoretic mobility distributions and probit analyses of PMNs from (a) a typical normal healthy subject and $(b)$ a patient with $R A$. 
ADHERENCE ASSAY

Nylon fibre which had been washed on three separate occasions with $0 \cdot 1 \mathrm{M} \mathrm{HCl}$, distilled $\mathrm{H}_{2} \mathrm{O}$ and Medium 199 containing $10 \%$ fetal calf serum was gently packed into the barrel of a $10 \mathrm{ml}$ plastic syringe to a depth of one inch from the narrow orifice. Ten million PMNs suspended in medium 199 with $10 \%$ fetal calf serum were added to the column (narrow orifice being closed) and incubated for 30 minutes at $37^{\circ} \mathrm{C}$. The non-adherent PMNs were eluted by several washes with medium 199 .

\section{STATISTICAL METHODS}

Student's $t$ test was used to determine the significance of differences between the means of two groups.

\section{Results}

Fig. 1 shows a typical EPM histogram of PMNs isolated from the blood of a normal subject and a patient with RA. Probit analysis of the different speeds of migrating PMNs identified two and occasionally three distinct electrophoretic subpopulations. Those PMNs with a high surface charge (i.e., cells contained in the histogram blocks nearest

Table 1 Longitudinal study of the electrophoretic distribution of blood PMNs from two normal healthy subjects

\begin{tabular}{|c|c|c|c|c|}
\hline \multirow[t]{2}{*}{ Subject } & \multirow[t]{2}{*}{ Months } & \multicolumn{3}{|c|}{$E P M\left(\mu u n . c m . s^{-1} . V '\right)$} \\
\hline & & Population I & Population II & Population III \\
\hline \multirow[t]{4}{*}{ A } & 1 & $0.91(90)^{*}$ & $0.85(8)$ & $0.78(2)$ \\
\hline & 2 & 0.92 (9)) & $0.84(10)$ & \\
\hline & 8 & $0.90(85)$ & $0.81 \quad(12)$ & $0 \cdot 80(3)$ \\
\hline & 20) & $0.91 \quad(84)$ & $0.83(11)$ & $0 \cdot 80(5)$ \\
\hline \multirow[t]{3}{*}{ B } & 1 & $0.91 \quad(85)$ & $0.82(7)$ & $0.79(8)$ \\
\hline & 11 & $0.90(85)$ & $0.85(9)$ & $0.80(6)$ \\
\hline & 17 & $0.91 \quad(84)$ & $0.86(11)$ & $(0 \cdot 80(5)$ \\
\hline
\end{tabular}

*Numbers in brackets denote percentage of cells ascribed to that population. the vertical axis) are referred to as population I $\left(\mathrm{EPM}>0.90 \mu \mathrm{m} . \mathrm{cm} \cdot \mathrm{s}^{-1} \cdot \mathrm{V}^{-1}\right)$ and the others, in decreasing order of surface charge, as population II (EPM 0.80-0.89 $\mu \mathrm{m} . \mathrm{cm} \cdot \mathrm{s}^{-1} \cdot \mathrm{V}^{-1}$ ), and population III $\left(\right.$ EPM $\left.<0 \cdot 80 \mu \mathrm{m} . \mathrm{cm} \cdot \mathrm{s}^{-1} \cdot \mathrm{V}^{-1}\right)$. For normal subjects the EPM and percentage distribution of cells within these subpopulations showed only minor fluctuations as demonstrated by repeated tests on six volunteers over a 20 month period, two of which are shown in Table 1. Table 2 shows the results of

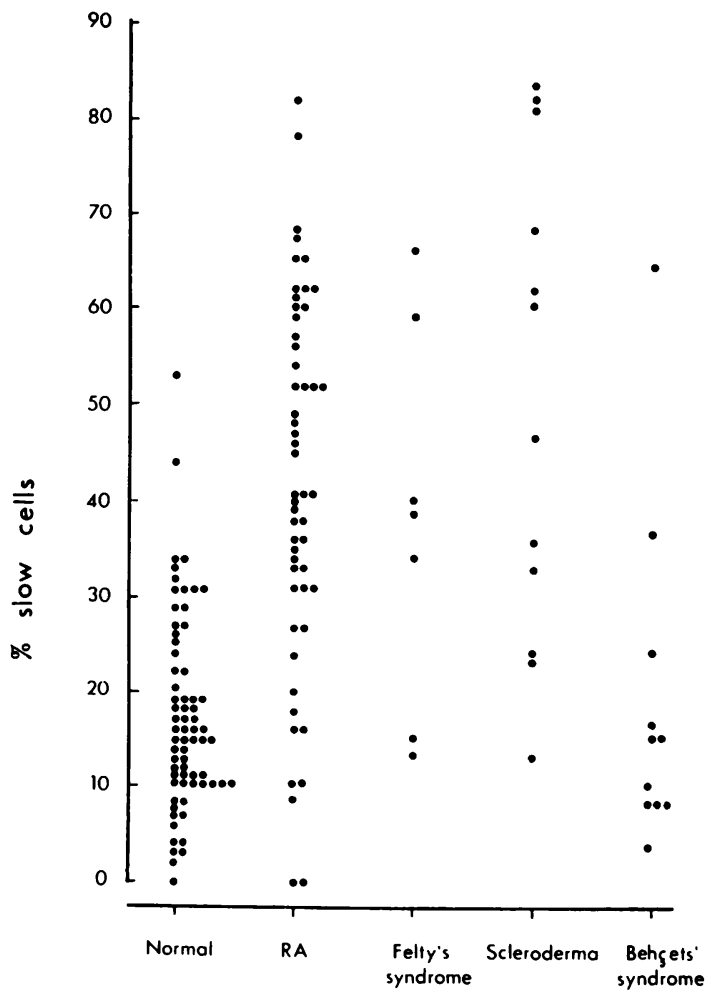

Fig. 2 Comparison of the distribution of the slow population of PMNs from normal subjects with that for patients with RA, Felty's syndrome, scleroderma, and Behçet's syndrome.

Table 2 Distribution of electrophoretic subpopulations of PMNs in the blood of normal healthy subjects and patients with $R A$

\begin{tabular}{|c|c|c|c|c|c|c|}
\hline \multirow[t]{3}{*}{ Subjects } & \multicolumn{6}{|c|}{ Electrophoretic subpopulations } \\
\hline & \multicolumn{2}{|l|}{$I$} & \multicolumn{2}{|l|}{ II } & \multicolumn{2}{|l|}{ III } \\
\hline & $E P M^{*}$ & $\%$ & $E P M$ & $\%$ & $E P M$ & $\%$ \\
\hline $\begin{array}{l}\text { Normals }(n=69) \\
\text { RA }(n=53)\end{array}$ & $\begin{array}{l}0.91(0 \cdot 01) \\
0.91(0 \cdot 01)\end{array}$ & $\begin{array}{l}83(10) \\
58(19)\end{array}$ & $\begin{array}{l}0.84(0 \cdot 02) \\
0.83(0 \cdot 02)\end{array}$ & $\begin{array}{l}13(17) \\
31(15)\end{array}$ & $\begin{array}{l}0.77(0.03) \\
0.76(0.03)\end{array}$ & $\begin{array}{l}4(5) \\
11(10)\end{array}$ \\
\hline
\end{tabular}

${ }^{*}$ EPM values are expressed as $\mu \mathrm{m} . \mathrm{cm} \cdot \mathrm{s}^{-1} \cdot \mathrm{V}^{-1}$ (standard deviation). 
measuring surface charge distribution on PMNs isolated from the blood of 53 rheumatoid patients and 69 normal samples. There was a significant decrease in the representation of population I ('fast' cells) in the RA group (prevalence $58 \% ; \mathrm{p}<0 \cdot(001)$. Correspondingly, the representation of populations II and III ('slow' cells) was increased in patients with RA (prevalence $42 \% ; \mathrm{p}<0.001$ ). Although the EPM values of individual subpopulations in RA corresponded with those of normal subjects, two thirds $(35 / 53)$ of rheumatoid samples contained a percentage of 'slow' cells (i.e., with EPM $<0.9(0)$ higher than two standard deviations above the normal mean (i.e. $30 \%$ ), while this was seen only in $10 / 69$ normal samples.

To ascertain if the increase in the slow population was a general consequence of inflammation rather than an observation peculiar to RA, electrophoretic determinations were performed on PMNs isolated from the blood of patients with other rheumatological disorders. Fig. 2 shows that the slow population was increased in the blood of patients with RA (mean $42 \% ; \mathrm{p}<0.001$ ), Felty's syndrome (mean $38 \% ; \mathrm{p}<0.001$ ), and scleroderma (mean $51 \%$; $\mathrm{p}<0.001)$ but not in patients with Behçet's syndrome (mean $18 \%$ ) when compared with normal subjects (mean 17\%).

Electrophoretic determinations were also performed on synovial fluid PMNs isolated from patients with RA. Of the 13 samples examined, only two presented an EPM profile similar to that seen with blood PMNs from normal healthy subjects $\vec{\circ}$ (Table 3). Interestingly, both of these aspirates were obtained from the left and right knee joints of a patient with RA during one visit to the clinic. Overall, the percentage of synovial fluid PMNs ascribed to population I was significantly less (mean $31 \% ; \mathrm{p}<(0 \cdot() 01)$ than that of blood PMNs obtained or from any of the patient groups. Many of the synovial of fluid PMNs often possessed the lowest EPM recorded in this study.

When blood PMNs from patients with RA were applied to nylon fibre columns and subsequently eluted it was the cells of a low surface charge that

Table 3 Electrophoretic analysis of synovial fluid PMNs obtained from knee aspirates of 12 patients with RA

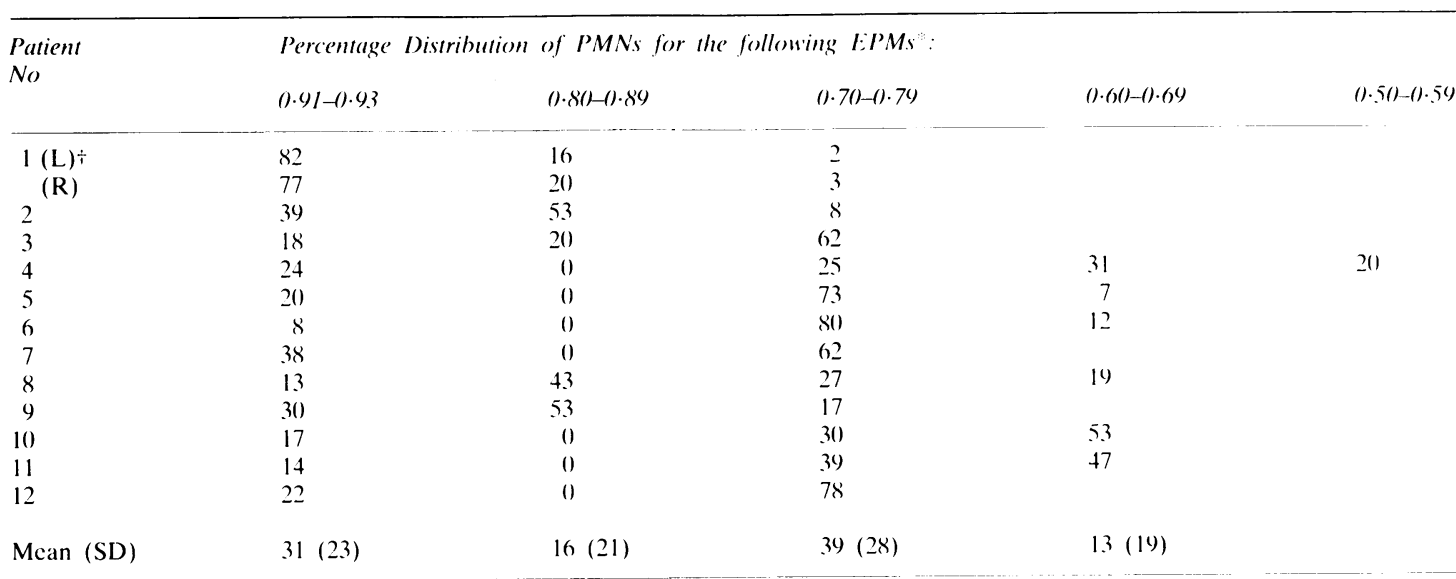

${ }^{*}$ EPM units are $\mu \mathrm{m} . \mathrm{cm} . \mathrm{s}^{\text {I. }} \mathrm{V}$ I

tFor patient No 1 PMNs were obtained from the left (L) and right (R) knec joints.

Table 4 Electrophoretic profile of PMNs from four patients with RA before and afier passage through nylon fibre columns

\begin{tabular}{|c|c|c|c|c|c|c|c|c|}
\hline Patient No & $l$ & & 2 & & 3 & & 4 & \\
\hline $\begin{array}{l}\text { Electrophoretic } \\
\text { population }\end{array}$ & $I$ & $I I+I I I$ & $l$ & $I I+I I I$ & $I$ & $I I+I I I$ & 1 & $I I+I I I$ \\
\hline \multicolumn{9}{|l|}{ Percentage PMNs } \\
\hline Before column & 51 & 49 & 44 & 46 & 69 & 31 & 73 & 27 \\
\hline After column & 92 & 8 & 88 & 12 & 97 & 3 & 87 & 1.3 \\
\hline
\end{tabular}


were preferentially retained (Table 4 ). These results suggest that PMNs of a low EPM are more adherent than cells of a higher surface charge.

\section{Discussion}

This study has shown that blood PMNs of normal healthy subjects and patients with rheumatological disorders often consist of at least two electrophoretic subpopulations with most of the cells residing in the population of a high surface charge. For normal healthy subjects the EPM values and percentage distribution of cells ascribed to these subpopulations showed little fluctuation over several months. Although the EPMs of the subpopulations in RA were identical to those shown from normal subjects, they often contained significantly more cells of a low surface charge, which were selectively retained on nylon fibre columns. This increase in the slow population was not confined to RA as shown by the similar finding with PMNs from patients with Felty's syndrome and scleroderma but not with PMNs from patients with Behçet's syndrome.

From previous demonstrations that a decrease in cell surface charge is associated with an increase in adherence ${ }^{5}$ the present data could be interpreted as suggesting that the adhesiveness of RA PMNs is greater than that of control PMNs. We recently showed, however, that there was no difference between the adherence properties of RA and control PMNs to cultured porcine endothelium. ${ }^{15}$ The apparent anomaly of these observations is probably related to a difference in experimental conditions. In the adherence studies most experiments were undertaken with serum present in the culture media, whereas all electrophoretic determinations were undertaken in the absence of serum. When the adherence assay was performed without serum the small number of blood PMNs attaching to endothelium made it difficult to evaluate any significant changes between the normal and RA groups. Interestingly, the adherence of RA synovial fluid PMNs to endothelium in the absence of serum was greater than that of matched blood PMNs, and in the present study many of the synovial fluid PMNs possessed the lowest recorded surface charge.

Scanning electron microscopy of blood PMNs from patients with RA has shown morphological characteristics distinct from those of normal PMNs, ${ }^{16}$ and such changes may reflect an alteration in the expression of membrane glycoproteins, whose ionogenic groups determine the electronegative nature of the cell surface. The very low EPM of the synovial fluid PMNs may represent a loss of membrane associated, $\mathrm{N}$-acetylneuraminic acid containing glycoproteins, whose decreased expression relates to the impaired chemotaxis and phagocytosis of synovial fluid PMNs. ${ }^{17}$ is Although previous reports have shown that a decrease in surface charge increases the phagocytic activity of macrophages, ${ }^{56}$ there may not be a single direct relation between a lowering of the EPM and an enhancement of cell function. It is conceivable that an augmentation or impairment of the functional activity of phagocytic cells depends upon the extent of PMN charge reduction. Experiments are in progress to examine this possibility.

Blood PMNs are known to consist of a circulating and marginating pool of approximately equal distribution, ${ }^{19}$ the circulating PMNs being located in the axial stream, and marginating PMNs in contact with vascular endothelium. The slow population identified in this study may contain a proportion of marginating PMNs which are not firmly bound to the vascular wall. Hence an increase of the slow population could represent an increase in the marginating : circulating PMN ratios. The leucopenia associated with Felty's syndrome is believed to be a result of an increase in the number of marginating cells, ${ }^{20}{ }^{21}$ though as far as we are aware there have been no reports of a disturbance between the circulating and marginating PMN pools in patients with RA and scleroderma.

That the slow population was increased in PMNs from patients with scleroderma was unexpected in that, as far as we are aware, these cells have not been accorded an active role in the pathology of this disease. Serum samples from patients with scleroderma are cytotoxic for cultured vascular endothelium, ${ }^{22} 23$ and as a protease dependent mechanism has been described ${ }^{24}$ it is plausible that some of the agents inducing cytotoxic activity, which may include the reactive oxygen metabolites, originate from PMNs. Support for this view stems from the recent demonstration that the chemiluminescence of PMNs from patients with scleroderma is greater than that of controls. ${ }^{25}$ Thus in scleroderma an increase in the slow population may be associated with a particular stage of activation that is not seen in patients with Behçet's syndrome, where the PMNs display an in vitro chemotactic hyperresponsiveness ${ }^{26} 27$ but an impaired migration through skin abrasions into chambers in vivo. ${ }^{27}$

A decrease in surface charge may result from the acquisition of more electropositively charged groups on the membrane, the loss of ionogenic groups containing $\mathrm{N}$-acetylneuraminic acid, or their masking by circulating soluble factors. The last possibility was investigated in the accompanying paper. ${ }^{28}$

\section{References}

1 Weissman G. Activation of neutrophils and the lesions of rheumatoid arthritis. J Lab Clin Med 1982; 100: 322-33. 
2 Burkhardt H, Schwingel M. Menninger H. McCartney M W, Tscheche $\mathrm{H}$. Oxygen radicals as effectors of cartilage destruction. Direct degradative effect on matrix components and indirect action via activation of latent collagenase from polymorphonuclear lcukocytes. Arthritis Rheum 1986; 29: 379-87.

3 Hollingsworth J W. Siegel E R. Creasey W A. Granulocyte survival in synovial exudatc of patients with rheumatoid arthritis and other inflammatory joint disease. Yale J Biol Med 1967: 39: 289-96.

4 Lichtman M A. Weed R I. Alteration of the cell periphery during granulocyte maturation: relationship to cell function. Blood 1972; 39: 301-16.

5 Weiss L. Mayhew E. Ulrich K. The effect of neuraminidase on the phagocyte process in human monocytes. Lab lnvest 1966: 15: $13(04-9$.

6 Nagura H, Asai J, Katsumata Y, Kajima K. Role of electric surface charge of cell membrane in phagocytosis. Acta Pathol Jpn 1973; 23: 279-90.

7 Brown K A. Collins A J, Holborow E J. Cell electrophoretic analysis of lymphocytes and polymorphonuclear cells from patients with rheumatoid arthritis. Lancet 1977: i: 114-7.

8 Howe G B. Fordham J N, Brown K A. Currey H L F. Polymorphonuclear cell function in rheumatoid arthritis and in Felty`s syndrome. Ann Rheum Dis 1981; 40: 370-5.

9 Ropes M W, Bennett G A. Cobb S, Jacox R, Jessar R A. Revision of diagnostic criteria for rheumatoid arthritis. Bull Rheum Dis 1958; 9: 175-6.

10 Subcommittec for Scleroderma Criteria of the American Rheumatism Association. Preliminary criteria for the classification of systemic sclerosis (scleroderma). Arthritis Rheum 1980; 23: $581-90$.

11 Mason R M. Barnes C G. Behçet's syndrome with arthritis. Ann Rheum Dis 1969; 28: 95-103.

12 Dioguardi N, Agostini A, Fiorella G. Lomanto B. Characterisation of lactic dehydrogenase of normal human granulocytes. $J$ Lab Clin Med 1963; 61: 713-23.

13 Prece A W. Light P A. The macrophage electrophoretic mobility (MEM) gest for malignant disease. Further clinical investigations and studies on macrophage slowing factors. Clin Exp Immunol 1974; 18: 543-52.

14 Brown K A. Embling P H F. Perry J D. Holborow E J. Electrophoretic behaviour of blood and synovial fluid lymphocytcs in rhcumatoid arthritis. Clin Exp Immunol 1979; 36: $272-8$.
15 Shechan N J. Brown K A. Perry J D. Chasty R C, Yates D A H. Dumonde D C. Adherence of rheumatoid polymorphonuclear cells (PMNs) to cultured endothelial cell monolavers. Ann Rheum Dis 1987: 46: 93-7.

16 McCarthy D A. Holburn C M. Pell B K. Moore S R. Kirk A P Perry J D. Scanning electron microscopy of rheumatoid arthritis peripheral blood polymorphonuclear leucocytes. Ann Rheum Dis 1986; 45: 899-910.

17 Turner R A. Schumacher H R. Myers A R. Phagocytic function $\mathbb{\mathbb { Q }}$ of polymorphonuclear leucocytes in rheumatic disease. J Clin
Invest 1973; 52: 1632-5.

$18 \mathrm{Kemp}$ S A. Brown S. Brooks P M. Neoh S H. Migration of $\vec{O}$ blood and synovial fluid neutrophils obtained from patients with rheumatoid arthritis. (lin Exp Immunol 1980) 39: 240-6.

19 Athens J W. Raab S O. Haab O P. et al. Leukokinctic studics. III. The distribution of granulocytes in the blood of normal subjects. J Clin Invest 1961: 40: 159-64.

20) Vincent P C. Levi J A. Macqueen A. The mechanism of $A$ neutropenia in Felty's syndrome. Br J Haematol 1974: 27: ov $463-75$

21 Joyee R A. Boggs D R. Chervenick P A. Lalezavi P. Neutrophil kinctics in Felty's syndrome. Am J Med 1980: 69: 695-7(1)2.

22 Cohen S. Johnson A R. Hurd E. Cytotoxicity of sera from patients with scleroderma. Arthritis Rheum 1983; 26: 17(1-8.

23 Shanahan Jr W A, Korn J H. Cytotoxic activity of sera from scleroderma and other connective tissue diseases. Arthritis Rheum 1982: 25: 1391-5.

24 Kahalch M B, Leroy E C. Endothelial cell injury in scleroder- $\infty$ ma. A protease mechanism. J Lab Clin Med 1983; 101: 553-60.

25 Kovacs I B. Thomas R H M. Mackay A R. Rustin M H A. Kirby J D T. Increased chemiluminescence of polymorphonuclear leucocytes from patients with progressive systemic sclerosis. Clin Sci 1986; 70: 257-61

26 Matsumura N. Mizushima Y. Leucocyte movement and colchicine treatment in Bchçet's discase. Lancet 1975; ii: 813 .

27 James R W. Walker J R. Smith M J H. Abnormal polymorpho- $\overrightarrow{\overrightarrow{0}}$ nuclear leucocyte chemotaxis in Behçet's syndrome. Ann Rheum Dis 1979; 38: 219-21.

28 Brown K A. McCarthy D. Perry J D. Dumonde D C. Reduction of the surface charge of blood polymorphonuclear cells by rheumatoid scra amd heat induced aggregated human IgG (HAGG). Ann Rheum Dis 1988; 47:000-0. 